\title{
The Cultural Expression of Xunduu (Coupling) in Oromo Knowledge of Gender
}

\author{
Ginbar Nagara \\ Unit of Liberal Arts, School of Liberal Arts and Social Sciences, Adama Science and Technology University, Adama, Ethiopia
}

Copyright $\mathrm{C} 2017$ by authors, all rights reserved. Authors agree that this article remains permanently open access under the terms of the Creative Commons Attribution License 4.0 International License

\begin{abstract}
The paper has aimed to propound the conception of femininity and masculinity in the traditional expression of gender in the Oromo mainstream culture, the xunduu (coupling) Synopsis. Xunduu is a bipolar means of expressing female and male overall organizations and relationships in the universe in pairing order of corresponding arrangement. Xunduu is gada born Oromo knowledge of gender which states about the general organizational arrangement, the overall power relationships, responsibilities and roles between husband and wife. The research was conducted in Oromiya. Data were mainly collected from literature and through systematic interview of female and male elders, observation of their cultural landscape and ethnographic objects. The finding indicates that, Xunduu is a manner of expressing a wife-husband relationship in replicating to biological sexual beings, non-biological and non-sexual things which are essential and respected, ordered in pairing and corresponding arrangement in their culture. The result also shows that from the nature of objects replicating gender and the methods of presentation, xunduu was a means to pursuing the practices of gender bipolar in the egalitarian gada ethos. It is recommended that as the culture is under strong pressure from internal and external forces, it needs to work towards preserving and enhancing such thoughtful wisdom towards gender empowerment.
\end{abstract}

Keywords Xunduu, Gender, Gada, Wife-husband

\section{Introduction}

Feminine-masculine is a biological opposite sex-based socio-cultural expression to indicate female and male relationships. Female-male relationship is the commonest form of manifestation to gender and its expressions in various manners of life including labor division. However, gender has been discussed as a means in which feminine opportunities was restrained in the pretext of biological sex disparity. Subsequently, the subject has become one of the most heated and debated issues in the contemporary world [9, $13,17]$.

The Oromo, like any group of people, is a gendered society and they are not exceptional to the ecstasy and agony experiences. Nonetheless, the concept of gender is varying across culture, society, education, production system, and other determining factors [9, 11]. Accordingly, a cultural way to the expression of femininity-masculinity in the Oromo worldview is xunduu (coupling) based gender bipolarity. The Oromo, the single largest nation in Ethiopia, have inhabited over a wider part of the country and they speak their language called Afan Oromo. The Oromo have their own long generational egalitarian socio-economic, political, administrative and military system called the Gadaa, which has served as a guiding principle for the nation as a whole $[1,15]$.

Xunduu is a bipolar means of expressing female and male overall relationships in pairing order of corresponding arrangement. Xunduu states how the general organizational arrangement, the overall power relationships, responsibilities and roles in gender are held at all levels of life. As wider as is human interactions, xunduu is female-male multidimensional relationships expressions in pairing of various entities and objects which simulate gender roles and functions.

In its underlying point of tradition, female and male beings are permanently interrelated and ever inseparable family life relational builders, which are customarily expressed in duality, as an expressional and representational to cohesive social and natural world. To this end, Xunduu is the ultimate means of expressing female and male bipolar relationships contrary to solitude and un-polar relations. It is believed in the Oromo tradition that wife-husband are linked in marriage for full life and form a base of their society; they are never delinked and it is more than appalling to express them in a solitude manner. Solitude is halving as an expression of separateness, disconnectedness and incompleteness, while pairing is something in connection and wholeness. Accordingly, beyond loneliness it is meant matchless which can result from physical and mental abnormality and social incompetence. It is disrespectful for 
an average adult to remain unmarried and/ delinked from marriage. This type of gender based constructions has gone beyond the expressions of human relationships that it is also dealt with non-human affiliations in the universe given by them wife-husband synopsis. As it will be dealt with in the upcoming discussion, it is a norm than common for every major important thing in the universe to exhibit normality by being chained in one to the other correlations of gender bipolarity to hold its equivalent opposite partner given by a wife-husband synopsis.

In order to qualify what the tradition requires from an average healthy person, it is always a norm for someone to marry and stick to someone in marriage for full life. Normality, in this regard, is defined with marriage status consistency and the knowledge of managing ones family healthily. Marriage in Oromo gada system is beyond the need to meet reproduction demand and form family bondage at the hearts of the society, as every individual is necessarily part of the whole and the group than separate and independent. Marriage is sources of respect and recognition to raise to most the important positions and power in the gada system. As to Dereje [6] any unmarried and divorced is considered incompetent to compete and hold gadaa leadership.

Similarly, bipolar gender expression is a commonest practice in the tradition of the western world (mostly in Europe) $[13,17]$. According to the literatures, the west continuum oppositions for female-male relationships are contrastive as follows: subject-object, essence-appearance, culture-nature, passion-reason and passive-active respectively. Adding that, the arrangement appears hierarchical, having the man at the top and the wife subordinate. This spills stereotypic behavior assuming men as aggressive, competitive and instrumentally oriented and women as passive, cooperative and expressive.

But, it is argued that hierarchical system is an antithesis to egalitarian $[12,14]$. The egalitarian socio-cultural structure deflates hierarchy and one to the other subordination and thus, the Oromo gada system is founded on indigenous democratic ethos $[1,11,12]$. Including in the aforementioned works, research in gender area clearly elucidates the reasonable positions of gada with feminine and acclaims gender relationships at its hearts. The Gada system was basically founded on arduous and physical laborious tasks like military, hunting and other outdoor services, which were the major compulsory requirements from each and every individual of the member in order to best qualifying for assuming the most important leadership positions $[1,9,4,11]$. As the result, opposite to male, female were engaged in life-saving and other indoor tasks as it was believed to be difficult for them to take part in activities undertaken at far distance and life-taking which were supposed to stop reproduction. The tasks were thought to be difficult for females who were engaged in nurturing and reproduction. Discussions made in all the aforementioned literatures corroborate, the presence of gada-born feminine led gender imbalance regulating institutions namely the feminine stick for power (siinqe), the power of the mother of fertility (atete), the feminine council in the gada system (saddeta) and the notion of sacredness (wayyu). Nevertheless, research works so far conducted on Oromo knowledge of gender have not underlain this fundamental notions rooted at the hearts of the gada system. Since the end of the $19^{\text {th }}$ century, the gada system has come to decline as the result of Abyssinian conquest of the Oromo and discouraged its practices. Nonetheless, gada is reviving since the 1990s and playing pivotal role in unifying the Oromo nation. The theme of xunduu is important in understanding the populace indigenous knowledge of gender bipolar to assist the empowerment efforts in contemporary world.

\section{Methodology and Methods}

Like most social science researches, this paper has dealt with culture that involves claims of values and rights. The study was conducted in combining historical and anthropological methodologies. Methods of data collection from secondary and primary sources through literature review, interview, personal observation and analysis of cultural objects were employed. The data were systematically organized, analyzed and interpreted. The research was mainly conducted in Oromiya and involved both male and female elders and custodian commoners. Although the issue was fully apparent, while the gada system was actively in use among the Oromo before the $20^{\text {th }}$ century, there is actual limitation in historicizing the theme as the work reflects both anthropological and historical approaches as well.

\section{Result and Discussion}

\subsection{The Uumee-uumaa Synopsis}

One of the first fundamental views with the Oromo knowledge of gender ideology is rooted in the indigenous belief system on which the gada system is based and named Waaqeffannaa (the belief in supreme divine God, Waaqaa) $[4,9]$. In Oromo indigenous religion, Waaqeffannaa mythology (dhugeeffanna) the first creature is said to have unrecognized sexual identity. This genderless earliest creature is believed to be identified with the name Horoo, which was turned into female and male beings by a glance of God (Waaqaa) [1, 6].

This particular religion utters that the earliest independent female and male divine beings are believed to be the origin of all human populations and became genesis in respective to ones sexual identity. This earliest female-male productive divine beings are expressed to be belonging to a twin realms named the Umee (the She/the Feminine Divinity) and Umaa (the He/the Masculine Divinity)[3,9]. Thus, it is believed that female and male generations are fundamentally stemmed from these gender based dual origins. 
Opposite biological sex based realms of female and male of the Oromo knowledge of gender is indicated as:

The She Realm (Uumee) $\Longleftrightarrow$ The He Realm (Uumaa)

This gendered form of synopsis which communicates the origin of everyone following his/her respective biological opposite realm has presented independent-dependent manner of relationships between female and male. The realm does not convey a derivate and subordinate relationship between female and male succeeding generations.

As indicated above, the uumee realm is believed to be the feminine divinity for fertility and fecundity to the whole human population and generation, as opposed to the male. In the Oromo oral tradition a dominant saying that Uumeen Walaabuu Baate means all creatures came out of Walabu (the Oromo concept of creation and the universe out of which creatures appeared). Similarly, when odd events happen the Oromo say, erga dhuftuun dhuftee uumeen Walaabuu Baatee, dubbii akkanaa aggarree hin beeknu, meaning after creation we have never heard (seen) such a thing $[1,6]$. This implies the creation of all life from dual origins and fertility in feminine form. There were also other lesser Deities prayed for reproductive purposes such as Ateetee, Maaramaa [1,6,16], Aayyoo Baar, etc [8].

\subsection{The Synopsis of Non-biological Non-sexual Gendered Entities}

In the tradition gender ideology also raises the conception about femininity-masculinity in association with simulated objects and things of the non-biological and non-sexual world. At this point, there are natural and social entities which at all are not known with their sexual identity but taken to express female-male relationships in the society. There are some non-biological non-sexual entities which are used to represent female-male relationships given by gender identity in between them in their functions, roles, social position and space they assume in relation to the other. In this regard, in replicating gender-based human relationships wife-husband relationships are constructed between two things which are fundamentally genderless. On the basis of this assumption, correlation between genderless elements is made to entice their organization in the universe which in turn will be simulating wife-husband pairing form of gender relationships. Some of the gendered objects given feminine-masculine representations are as indicated below:

\begin{tabular}{|c|c|c|}
\hline Mother/Wife & & Father/Husband \\
\hline Earth (Lafaa) & & God/Sky (Waaqaa), \\
\hline Culture (Aadaa) & & Law (Seeraa), \\
\hline Water (bishaa) & 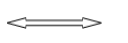 & Grass (Marga), \\
\hline Night ( Dukkanaa) & $<$ & Daytime (Ifa), \\
\hline Left-side ( Bitaa) & & Right-side (Mirgaa), \\
\hline $\begin{array}{l}\text { Down-side position } \\
\text { (Jalaa) }\end{array}$ & & $\begin{array}{l}\text { Up-side position. } \\
\text { (Irraa), etc, [8] }\end{array}$ \\
\hline
\end{tabular}

In the culture of the Oromo of Arsii culture, when a woman presents any complain to the assembly, it is usual to recall the utterances in front of the assembly saying, Waaqaa fi lafaa (for heaven and earth), Margaa fi bishan (grass and water), ifaa fi dukkana (for light and darkness), aadaafi seera (for custom and Law). Women are said to have made complaint and the utterance to restore general peace and order. They utter in front of elders who represent truth and laws to raise and restore justice and equality when it is being violated. For every major important thing which is presented above that the male is represented, female is by the side opposite of him.

The duality of God/sky (Waaqaa) and the earth (Lafaa) constitute the central avenue in Oromo indigenous belief system. Bartles [3] explains, the sky is like a father who goes away while Earth is like a mother; she is always with us. The sky causes and dropps rain but does not raise life alone without the earth, which grows grass and food to living creatures so does the latter. The duality of the sky and the earth, for instance, is explicated in husband-wife relationships. For instances, the following saying: waan Waaqni roobse dachiin biqilcha, which means what God causes to rain and the earth grows it[6].

In causing elements basic to life, the divine and earth are gendered. In gendered universe the sky represents father/male and the earth represents his mother/wife. Creatures in between the two are children. Here, a bipolar of feminine and masculine implies the necessity that both to be coincide to sustain and ensure the whole living and non-living. Only when both communicate creatures can live peacefully, and so does the replica female and male relationships [3].

In the Oromo customary law, there are two distinct social terms custom (aadaa) and Law (seera). The former is known to individuals who belong to the same culture, while the latter is only known to those who specialize in it. Custom refers to custom, habit, tradition, way of life etc and is a symbol of identity, unity and oneness. Custom and Law are highly integrated to maintain the society in unity and the former protects the latter. It indicates females are more appropriate for maintenance of culture while the males are for the laws [6]. The view assigns able bodied male to provided protection for his family including his wife from an enemy. But, male seeks his wife's ritual and spiritual remedy.

In Oromo cultural expression, a hope of change is vastly submitted to the power of nature and God at night time. It is usual to hear among the Oromo expressing their hopes for change "waan halkan/dukkanni fidu maaltu beeka" "we do not know what thing/change the night bring to us?. The night is seen as a reproduction time as dukkanni/halkan rimessaa (fecund). This means night causes things to reproduce and replicate. The day (guyyaa) light-time is relatively considered to be 'infertile' goga as male is considered a dried-womb. At the day-time many tasks are driven through the power of light the muscular force features masculinity. In terms of changes prevalence, the night is organic than the day. The night is characterized with perfection and tranquility. In brief, femaleness is associated with night through maternity, the power over fertility and reproduction 
primarily eventuated. The Oromo listens to various happenings at night and forecasts the coming life. However, it is still when only both combine that completeness eventuates and together they form a full/complete cohesive day. Otherwise, the solitary is unnatural and reversing law of nature.

\subsection{Non-sexual Organs of Human Bodies Gendered Synopsis}

Again gender relationships are expressed with the replicas of non-sexual human body parts. This presents female-male relationships as a direct replica of some biological organs of human body parts which are identical in existence, appearance and function. Under this category, as it would be presented below, different from the aforementioned ones, female-male relationships are given simulation with non-sexual, biological organs of human body. The expression is also different from the aforementioned that the entities are paired prevailing the sameness of female and male beings and to accomplish identical roles except a matter of social position differences. In this regard, some of the biological, non-sexual parts of human body which are given with gendered forms of expressions are as follows.

\begin{tabular}{|c|c|c|c|}
\hline Body & Parts Female/Wife & & Male/Husband \\
\hline The two & legs, left-side & $\Longleftrightarrow>$ & right-side \\
\hline The two hands, & left-side & $<$ & 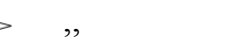 \\
\hline Eyes, & left-side & $\Longleftrightarrow>$ & $>$ \\
\hline Nostrils, & left-side & $\Longleftrightarrow$ & $>$ \\
\hline Ears, & left-side & $\Longleftrightarrow$ & $>$ \\
\hline Lips, & lower-part & $\Longleftrightarrow$ & upper part \\
\hline Tooth jaws, & lower part jaw & $\Longleftrightarrow>$ & $>$ upper part jaw \\
\hline
\end{tabular}

As it is seen from the above synopsis, female-male is identical and they form direct matching relationships except a matter of social arrangement and position-based differences. Otherwise, they are things of the same kind and category which carry out the same functions and roles that can support and enhance each other towards the wholeness than competitive and subordination.

Here, with regard to human body organs based wife-husband relationships the synopsis implicates a real human gender relationship that is made in right-left side organization. This right-left dichotomy in the Oromo culture is said to be showing the necessity for both to exist in pair and that one is needed for the other's presence and survival.

\subsubsection{The Right-Left Dichotomy Arrangement}

In Jeylan [9] the right-left dichotomy is presented to prevailing prejudices on female as the left hand side is believed to represent meekness. But, the background knowledge in Oromo tradition presents a different assertion. Accordingly, while the left hand side of human body part is compared to female, the right hand side is simulated with male. Comparing one to the other, the literary social meanings of the right and the left hand sides bear on the distinctions between both than prejudices. This social meaning is given with in terms of their major social roles to which each is accounted for. As it has been mentioned earlier at the beginning, the creationist mythology assigned the earliest and first female creature to the left side of her opposite partner, male. According to my informants, this is vivid from the creation mythology that propounds the rise of female to the left side of male, who assumed the right side. They say that, this is why male customarily clinches his female lover in his left hands [8].

The left-right dichotomy significantly winds around the key view of life-saving and life-taking realm to which the opposite sexes are attributable with their lesser muscular and physical realm. Culturally, it is uttered that, the left side is associated to non-fighting, non-violent (evade holding and throwing spear) and defending / shielding a spear thrown at by the opposite party are roles of the left hand side. Similarly, both feminine and left hand side assume overlapping roles of peace-loving, life-saving, non-fighting, and non-stubbing, while the right hand side symbolizes life taking and violent tasks of males with iron materials. This is the reason why a female carries ritual stick made from tree named siinqee and they never hold and use iron made stubbing materials [10]. The non-provoking, non-fighting and non-violent left hand side symbolizes peace.

Still, the customs are common in the family structure of the Oromo of Arsii. In Arsii family structure is represented with three forks of feminine ritual stick named siinqee Makkallaa. Siinqee Makkallaa stick holds three limbs on its head representing: the father, mother and children at the same time. In accordance, while the middle limb represents a husband, the left side stands for a wife and the right side limb symbolizes children [8]. It is the commonest one specifically in the southern parts of the Oromo of Arsii. Indeed, such values of the society have deep rooted practices and form close and profound understanding of their past socio-political and religious life.

Another indication to the left-right dichotomy arrangement customariness is the style the Oromo builds their houses. The Oromo build his/her sons houses' on his/her house's right and left, based on their seniority in ages. Accordingly, when the elder son constructs his house on the right sides of his family's house, the younger's is to be on the left side $[1,15]$.

\subsection{Gendered Insignias and Title Based Xunduu Synopsis}

Insignias and titles are the other means and ways to express gender in female-male and wife-husband relationships in Oromo worldview. There are title and high level insignias held by females and males which distinguish the roles and positions assumed by an individual person stick to his/her respective sex identity. Most of the time, in their formation, insignias are distinct to gender identity but each of the emblems is made to be identified with its own gender equivalent and corresponding. High level insignia are held by the male category for elevated political, religious and 
social power representation. But corresponding to every power holder male is a female who is as well identified by her insignias, which represents the latter to execute various issues in different fields of life [1,3]. Insignias are emblems of the socio-cultural life which perpetuate author and power, the positions and status of a holder person for law making process, its endorsement and execution, maintaining social rules and order as well.

According to the knowledge, for every major important power and positions a male holds, his wife stands on his sides, even though the reverse is unusual. This is the fact that as patriarchal dominating society, it is usual to see while male assume upper hand in most cases, becoming source of political power and authority for the whole than female. In this regard, female is ascended to an important political role through her marriage partner, male [1,8]. But, for every power a male assume, his wife is never missed to correspond to her husband. This is meant that for every power and prerogatives that the male enjoys, his female partner shares the corresponding prerogatives through the former. This sort of affiliations amid a wife and a husband could be elaborated through the following insignias:

\begin{tabular}{|c|c|}
\hline Female (Wife) & Male (Husband) \\
\hline The priestess & The priests \\
\hline (Qaallittii) & (Qaalluu) \\
\hline The mother of $\mathrm{Cacu}$ & The father of Kalacha \\
\hline (Haadha Caаcсuu) & (Abbaa kallachaa) \\
\hline (Made from shell) & (Wore on forefront) \\
\hline $\begin{array}{l}\text { Hanafala Gadaa } \\
\text { (made from leather) }\end{array}$ & $\begin{array}{l}\text { The father of Bokkuu } \\
\text { (scepter of power) }\end{array}$ \\
\hline $\begin{array}{l}\text { Siinqee } \\
\text { (wooden stick) }\end{array}$ & $\begin{array}{l}\text { Horooroo/waddeessaa } \\
\text { (stick hold at marriage) }\end{array}$ \\
\hline $\begin{array}{l}\text { Saddetaa } \\
\text { (female council } \\
\text { in gada assembly) }\end{array}$ & $\begin{array}{l}\text { saddetaa } \\
\text { (male council) }\end{array}$ \\
\hline
\end{tabular}

For every important positions of a male husband assumes, there is a feminine equivalence. They were possessed by the members of the first born clans in a single family and lineage. Boku, Kalacha and Caccu are held by an individual of the first class from the Oromo clan. Kallacha is held by the first born male spiritual leader named Abba kallacha (holder). Kallacha is a highly respected ritual symbol, an object for cursing and life-taking while its corresponding match opposite sex partner is Caccu, held by the wife who is named as Hadha Caccu (the holder) for blessing and life-raising symbolism. Hadha Caccu was a woman symbolic leader responsible for praying to abundance of well prospered fertility and invokes the Ume (the she creature) and Uma (the he creature). Kallacha represented the sky-God, while Caccu symbolized the earth. Besides male holder of Waddessa/Hororo, the feminine insignia is Siinqee. Siinqee is also an insignia for peace pacifier, as opposite to an iron material object like spear, knife, and etc held by male $[1,4]$. In this regard, women and men of similar gada class assumed symmetrical responsibilities.

\subsection{Roles Based Gendered Xunduu Synopsis}

Femaleness and maleness is also constructed around some contrastive roles which distinguish someone into a given sex identity based on obvious gender distinctions. The principle of gender-based contrastive role assumed between a wife and a husband have manifested one clear opposite of the other. This is basically lined up around the following parallel centric powers and social security: fertility and defense. The two major issues of security insurers from within and outside fundamentally include the following.

$\begin{array}{ll}\text { Female/wife } & \text { male/husband } \\ \text { Life-giving } & \text { life-taking } \\ \text { Fertility } & \text { dried womb } \\ \text { Spiritual } & \text { muscular } \\ \text { Domestic } & \text { wilder (hunter) }\end{array}$

In accordance with the knowledge, feminine is represented with fertility and fecundity qualifying task. Fertility and defense are the two most determinant factors for society. Fertility is a means to ensuring the continuation of generation tree seeds from within, and defense is protecting the land and country from conquest. Unless the balance of power in between both is maintained the question of survival and continuance is being threatened. Once female is life-giving class, tightened in birth and nurturing progeny, it is habitually impious to involve in an opposite realm activity. The more muscular is a higher life-taker engaged in outdoor activities and sinful for progeny, the more spiritual is a greater life-giver pursues fertility at indoor. Defending the land is an outdoor muscular physical activity which is indentified as male's prime role to sustaining society through life-taking task and longtime services. Outdoor activities mainly military, hunting and laborious tasks qualifying to the gadaa power transfer and assuming most important positions are fallen into masculine traits. The sinful male person through his life-taking nature can be relieved for him through his wife's blessing, ritual for purification and other God invoking means in their tradition. Otherwise, it is difficult for the male to see successful life unless his wise has not made sin purification ritual and spiritual activities.

This is what Jeylan [9] has stated that God (Waaqaa) listens to women's desire and instantly responds to it. Women are believed to have natured to meditate and invoke God than men and they are closer to nature in their nurturing and life-sustaining features. While the able bodied male pursue physical realm and the female does non-physical activities through their pure nature. It is a manner of assigning dissimilar into contrastive positions which are not competing and contending.

What Xunduu teaches about is how to regulate imbalances at some range of differences or continuum between opposing forces without elimination and subjugation. When opposites have formed mutual, the problem of contrasts would be resolved from reducing or causing imbalances in between the two forces. Opposites are governed against causing destructs with the principle of 
Oromo notion of distance and respect (safuu) [10]. Every side understands the other side opposites without intermix and elimination. It is the manner of leading contrasts side by side. The synopsis is aimed to keep a sort of natural regulation between divided halves from extremely causing disparaging consequences on universe.

\subsection{Gendered Behaviors and Manners of Xunduu Synopsis}

Again the knowledge of gender and its manifestation in Oromo is still established along certain feminine and masculine traits based behavior and manner. In this regard, the distinctions between female and male are dependent on the type of behavior and manner that one ought to reflect and develop in life and other found to see the person in accordance. These are used as separating boundaries and distinctions between female and male. The boundaries are most of the time non-crossable unless at certain limited gada age class.

Thus, certain characteristics features made to represent feminine and masculine identity. The following are some of the bipolar opposite characters traits that represent feminine and masculine.

$\begin{array}{ll}\text { Feminine } & \text { Masculine } \\ \text { Softhearted } & \text { hardhearted, } \\ \text { Soften } & \text { viscular, } \\ \text { Non-violent } & \text { non-surrendering, } \\ \text { Sociable } & \text { forceful, } \\ \text { Shrewder/discerning } & \text { impious, } \\ \text { Pious } & \text { sinful, } \\ \text { Sacred } & \text { vindictive, } \\ \text { Innocent } & \text { impolite, } \\ \text { Polite } & \text { unaffectionate, } \\ \text { Affectionate } & \text { disobedient, } \\ \text { Submissive } & \text { deterrent, etc } \\ \text { Conscience } & \end{array}$

The arrangement seems to be prevailing more of contrastive representation. As it has been indicated in the introducing part, similar to traditions in the most western society, female and male in Oromo have assumed contrastive continuum domains of life. However, the Oromo bipolar arrangement is the process of forming corresponding relationships between opposites towards wholeness in avoiding solitariness and lonesomeness, competing and subordination. The competing nature seemed to be intervened due to the egalitarian organization of the Oromo gada system itself, the power of arrangement behind the philosophy with regard to the synopsis and various feminine led institutions in the gada system. These are the feminine emblem for peace and security (the siinqe), qanafa, the notion of sacredness which confers respect upon the mother, virgin girl and postpartum (wayyuu), the notion which declares feminine supremacy in continuing generation tree seeds and spiritual power (atete), feminine section council in gada system (saddeta).
Irrespective of other things, particularly the socio-economic, geo-military, political, etc, conditions which determine both behavior and manner, feminine assumed more modest than the male. The male aggressive nature was dictated by the type of activity and responsibilities assumed mainly in relationships to masculine tasks like attack and defense. In contrast to this, the feminine is more of peaceful and finds spiritual remedies. Comparing both, from the civic point of view the feminine behaviors and manners are more of modest and signaled courtesy which is inarguably essential than its opposite.

It is mentioned in literature that anytime the ultimate goal of Oromo mottos was to be a leemmoo [7]. Leemmoo is believed to be the most humble, plain and modest behavioral and well mannered person. Characteristically, it is meant a descent, more of silent, affectionate, tolerance, patience, etc, of a civil character traits that any humble Oromo individual own to attain in life. The lemmoos are male higher social classes whose civility in manners and behaviors are tested that he should have dropped the masculine nature and imitate feminine in all of his aspects: dressing, urinating, eating, roles, and etc. The leemmoo was a person whose characters, personality and actions testified the utmost criteria of purity, truth and greatness and could only visit the religious center and the land of anointment, Abbaa Mundaa [7,8]. Modest behaviors are the absolute features of feminine which is favored and imitated by males of the higher class of gada (the pilgrims/ jilaas) who have reached the stage of tranquility, finishing their masculine duty. Their roles were fostering life through blessing, spiritual services, etc. Thus, modesty was a seminal trait that is commendable as the utmost qualifying behaviors and requirements for an individual of higher social, ritual and spiritual status. This, on the other hand, implies the customariness of gender reversal in Oromo society before the decline of the tradition with the demolishing of gada system of governance in the $20^{\text {th }}$ century.

\section{Lesson Based on the Nature of Correlated Entities}

The overall discussion presents various gendered forms of nouns, expressions and perpetuations which are made to represent female-male/wife-husband multidimensional ties. The tradition of Xunduu is, however, different from other forms of gender expression to prevail a customary manner of female-male relationships in simulating to various non-sexual elements. In Xunduu female and male are always bipolar of another, which underlined to be expressed in duality and this non-separateness, has showed against un-polar existence that is given by solitude expression.

Several entities varying from elevated social roles, beings of human body parts, behaviors and manners, to natural entities in replica are made to represent gender based organization and express the relationships. The paired 
entities used to represent female and male are reputed social objects which are absolutely respected for their essentiality in determining life, beyond any preconditions, due to the fact that their mistreatment is feared for causing instability and end of life.

As one can realize from the discussion, implying that the elements are highly fundamental and essential in their worldview, they do not present gender biases. At all points, none of these elements are despised, vilified and established on impartial relationships. Neither the ether nor the dual entity both in person and in combination have never assumed and presented one to the other a lesser/greater relationship.

No single paired entity and object prevails lesser and/ better than its corresponding. No part of the whole is subordinate and greater to the other as the power of each correlated entities and the rules for correlations regulate the whole relationships. Again the association is based on the conditions that the either side is only supporting its opposite roles and functions that pursued interdependence than dependent and one sided mutualism. On the other hand, it is a must to the either element, the other to survive. The surviving of one is only determined on its correlated matching party as the other cause the opposite continues and discontinues.

\section{Lesson from the Correlation Presentation Methods}

The multidimensional relationship expression to a female and a male being is made directly in person and simulated to various social and natural entities that are arranged in pairing and corresponding order. This manner of correlation is the process of arranging similar and/ dissimilar entities in corresponding arrangement. The paring relationship established on a continuum order is meant to evade un-polar and avoid exclusion from almost all important areas of life. This arrangement which seemed to be discouraging vertical communication was due to the influence of the egalitarian gada system. Almost major important things in the universe are chained, organized and arranged in one to one marriage relationships and governed by the rules of gender construction. The correspondence relationship pertains to what the other halves in wholeness. It is about the mechanisms to address the problems with regard to gender. Pairing underlies the need for marriage which is highly essential issue of security and Xunduu is about an expression against unmarried and divorce.

\section{Xunduu as an Expression to Non-human Worldview}

Beyond sex based human descriptions, gender in Oromo is given to portrait the relationships between other non-human and non-biological non-sexual elements, as their arrangement and organization is meant a healthier universe.
As Xunduu is an expression of human gender bipolarity in replica to non-human and non-sexual entities, it is meant to express a way the universe came to existence and held healthier. Female and male non-separateness are conveying the absolute ties of major things in the universe to regulate the balance of nature.

The expression is a portrayal to what form, organization and arrangement the universe and elements in the cosmos should hold in order to understand and recognize healthier life. This process of gendering non-sexual elements seems to underlying the places that are given to gender in their worldview and its implications on the later. This manner is an expressional to the continuation of generation tree seeds, wellbeing of universe and stability of family life. In accordance, the cosmos organization is held with female-male simulated perpetual harnesses and the outcome of the combined two determines the whole universe. This distinct philosophical thought in explaining the universe and other relationships beyond the human being in gender form of noun has served as the basic guiding principle in the Oromo worldview. Thus, gender is not only limited to the expression of biological sex based human relationships established between female and male, but it is about the creation of the universe, the balance of power arrangement, generation tree seeds, the manner of human organization, and so on.

Some of the manners which are used to identify female and male have triggered further differences in social space and functions. Xunduu is an alternative manner to solve biological sex disparity based differences in view of simulation and the objects as they are crucial in their worldview. In this regard, Хunduu has been designed to address gender-based biases and imbalances through a sort of harmonization as its prime concern. The creation of the universe is the subsequent result of gendered contrastive forces whose mutual coexistence and balance determined the whole thing. Unless both are coordinated and harmonized, no separate peace is prevailing for the either entity alone. Intermixing roles and functions and stepping into the either boundary are the most appalling negation in Xunduu except at certain age and class set of gada.

\section{Xunduu as Basic Principles and Pillars to Oromo Knowledge of Gender}

The expression of gender using simulation of various elements is aimed to instilling the knowledge into the minds of their child. Thus, female and male is what the objects are meant to one the other and the revesre is also true. Roles in a family between female and male children and wife-husband as well as father and mother are bounded according to the principles which determined peace and stability in the family and society as well. As some of the objects are highly reputable to the society, female and male are similarly implied through the representation which entails the 
necessary respect and protections for the natural elements and social objects. What a wife and a husband in a family to one the other is what a father and a mother as well as female and male are meant to a child in recognizing and assuming ones responsibility.

Another is the authenticity of gender reversal. Femaleness and maleness is also identified by the positions and roles that a particular individual can fully and actively assume and carried out in accordance rather than necessarily based always on biological sex distinctions. But, responsibility of an individual in the wholeness goes beyond sex identity boundary. In the gada system the first age set boys and girls are never identified by their sex. It is most usual that boys and girls under age eight are indentified with feminine noun of ishee (she). Again, the male spiritual leader (Qaalluu), the retired male gada class (gadaamoojjii) and the active gada leader ( $A b b a$ Bokkuu), unlike their male group, never hold iron made material for life-taking purpose. Besides, the male humble class (lemmo) and other pilgrimage male class were feminine in all of their aspects, acting, category, behaviors and manners. However, biological sex based separation and division is not a permanently established boundary owning that at certain age and status, particularly the first and last gada grade gender reversal is a bound $[7,8]$.

\section{Conclusions and Recommendation}

In Xunduu expressions of female-male beings bipolar arrangement, relationships are presented both in person and simulated to several entities varying from biological non-sexual to non-biological non-sexual categories, which are highly essential and honored. Xunduu explains what the female-male relationship would look like in cultural form of correlation to show the underlying inseparable and interrelatedness of one to the other. It seemed to be unique from traditional manner of coupling and binary expressions.

Coupling is a mannerism to expressing the relationships between two things and beings identical and/ opposite in essence and appearance. It is used to show independent and interdependent relationships between and among things formed bipolar. Thus, for someone who sees into the background knowledge of gender realizes the separation into female-male identity and activities along the labor division principles than otherwise. Assigning female and male into varying positions and roles by itself does not necessarily present prejudice unless the manner of arrangement does not prevail to encourage imbalance and dissect in picking order and subordinate way. Into what unequal positions and tasks both of them assigned simultaneously and differently prevail prejudice. Xunduu view of gender seems to be the way the populace have been addressing the problems of inequality and the sensitivity of the subject in their culture.

Various forms of representations in pairing order of corresponding arrangement and organization are made replicate wife-husband relationships. As such the representing entities are varying, owning to their category.
The discussions made in wide ranging representation pertain to the following conclusions. One, female and male are alike beings but only vary in social position and place held next to the other to form wholeness in separate. Second, female and male have assumed non-identical functions but only in common and in the presence of both that they could provide what are essential for others including the universe interdependently. Third, they form opposites in assuming contrastive roles which are held together for mutual relationships to maintain healthier universe. In all of the expressions, elements in Xunduu and female-male relationships are not competitive but a mutual one as the power of arrangement regulates it.

Those elements made to represent gender are highly crucial and fundamental whose absolute existences need to be set without mistreatment. The need to coupling is disclosing the compulsoriness and essentiality of one for the other and the whole in general. This is the fact that only the strong presence of one next to another would compel organic health. The universe is held from halves and opposites whose organization is corresponding.

In order to do so, thus, the paper underlies the need to understand society from the background and from its own cultural points of view. In doing so, such indigenous values can be helpful in gender empowerment areas. However, irrespective of this, the past position of female in the study area was dominated by their male partner and could never be free from their influence. Nonetheless, the condition of female was relatively better during the gada system than the worsening situations prevailed later under the regimes of the Ethiopia empire state. This happened with the demolishing of gadaa system of governance. But, in order to bring the experiences to the lights of today's gender empowerment, there is a need to issue the subject. The practice is limited to grass root level and its current positions are facing challenges from factors like globalization, expanding religion, modern education and including non-cultural conformity gender policy, etc.

Peculiar to the xиnduu tradition, besides the elevated status and higher recognitions of the entities paired to express gender, side by side arrangements prevails to corresponding order of arrangement. The social status of those simulated correlates and manner of their presentation does not prevail to deliberate and non-deliberate prejudices. It rather shows the manner in which major activities and areas of life a male presented, female must be by his side. In this regard Xunduu is a traditional means to fitting modern views and practices with the empowerment of female.

\section{REFERENCES}

[1] Alemayehu Haile. Gada System: The Politics Of Tulama Oromo. First Edition. Oromia Culture and Tourism Bureau. V.1, 2009. 
[2] Asmerom Legesse. Gada: Three Approaches to the Study of African_Society. New York: The Free Press, 1973.

[3] Bartels, L. Oromo Religion: Myths and Rites of the Western Oromo of Ethiopia - An Attempt to Understand. Reimer, Berlin. 1983.

[4] Daaniyaa. Waldaa Duudhaa fi Aadaa Oromo (Association of Oromo Culture and Value) Finfinnee, 2004.

[5] Damean, Diana. Media and gender: Constructing feminine identities in a postmodern culture. Faculty of History and Philosophy, Babes-Bolyi, University, Cluj Romania.

[6] Dereje Hinew. "Historical Significance Of Some Major Gadaa Centers In Oromia". .A.U School Of Graduate Studies, 2005.

[7] De Salviac, Maritial. An Ancient People Great African Nation: The Oromo. Ayalew Kenno/tras./ Oromia Culture and Tourism Bureau, 2008.

[8] Ibsa Tiruneh. "Aadaa: Ateeteen Kabaja Mirgaaf (Ateetee for respects of women's rights)(A. Kallacha Oromiyaa. /2002.

[9] Jeylan W. Hussein, “A Cultural Representation of Women in The Oromo Society", African Study Monographs, 25(3): 2004.
[10] Gemechu Megersa. "The Oromo world-view". In First interdisciplinary seminar of the IES. Nazareth. 1998.

[11] Kuwee Kumsa, "The Siqqee Institution of Oromo Women," in the Journal of Oromo Studies, vol. 4, nos. 1 \& 2, July 1991.

[12] Levine, Donald N. OROMO NARRATIVES. Journal of Oromo Studies Vol. 14. no 2 (July 2007), pp. 43-63.

[13] Manji, Tahira.. "Binary Oppositions". Online article, The Dr. Z Network, 2005.

[14] Markakis, John (1974) Ethiopia, Anatomy of a Traditional Polity, Addis Ababa: Oxford University Press

[15] Mohammed Hassen. The Oromo of Ethiopia. A history, 1570-1860. Cambridge: 1990.

[16] Negaso Gidada. History of the Sayyo Oromo of South Western Wallaga, Ethiopia from about 1730 to 1886. Addis Ababa. Mega printing Enterprise, 2001.

[17] Stets, Jan E. and Burke, Peter J.. "Femininity/Masculinity", in Edgar F. Borgatta \& Rhonda J. V. Montgomery (Eds.) ,Encyclopedia of Sociology, Revised Edition. New York: Macmillan. Pp. 997-1005. 